\title{
INDICAÇÃO GEOGRÁFICA PARA FRUTAS: CRITÉRIOS DE CONCESSÃO E OBJETIVOS, UMA ANÁLISE COMPARATIVA DE CASOS EUROPEUS E BRASILEIROS ${ }^{1}$
}

\author{
Larissa Bueno Ambrosini ${ }^{2}$ \\ Carlos Alberto Oliveira de Oliveira ${ }^{3}$
}

\begin{abstract}
RESUMO
As Indicações Geográficas (IG) são instrumentos que visam proteger e valorizar um produto cujas características e reputação estão diretamente relacionadas a sua origem. Tradicionalmente utilizadas por bebidas alcoólicas e por derivados de leite, as IG têm sido demandadas para frutas e outros produtos in natura. O objetivo desse trabalho é fazer uma análise comparativa da concessão de IG de frutas entre Brasil e Europa. Para isso, utilizamos a documentação que embasa a certificação de quatro tipos de frutas, duas na Europa, e duas no Brasil. Verificamos que, no caso europeu, a relação entre produto e território de origem, ou o efeito terroir, se apresenta de forma mais completa. No Brasil parece prevalecer uma visão de que as condições naturais (solo e clima) são suficientes para justificar uma IG. Não foi possível estabelecer relação histórica ou cultural dos produtos brasileiros com seus territórios de origem, nem a valorização de práticas agronômicas que tenham sido desenvolvidas localmente. Concluímos ponderando a necessidade de trazer à discussão os processos de certificação de origem atualmente em curso no Brasil e o aprofundamento da discussão conceitual em torno dos mesmos.
\end{abstract}

Palavras-chave: certificação de frutas, indicação geográfica, território.

\section{GEOGRAPHICAL INDICATION FOR FRUITS: CRITERIA FOR GRANTING AND OBJECTIVES, A COMPARATIVE ANALYSIS OF BRAZILIAN AND EUROPEAN CASES}

\begin{abstract}
Certifications of origin or Geographical Indication (GI) are instruments designed to protect and enhance a product whose characteristics and reputation are directly related to their origin. Traditionally used for alcoholic beverages such as wine and

\footnotetext{
${ }^{1}$ Esse estudo faz parte de um projeto de pesquisa financiado pelo CNPq que pretende levantar dados e discutir o potencial do "abacaxi terra de areia" em obter uma IG. Projeto: Potencialidades para a obtenção de Indicação Geográfica (IG) por parte do abacaxi (Ananas comosus) de Terra de Areia - RS aprovado no Edital MCTI/CNPq n.14/2013 - Universal.

${ }^{2}$ Graduada em Veterinária (UFRGS). Mestre em Desenvolvimento Rural (PGDR-UFRGS). Doutora em Gestão (Université de Bourgone-França). Pesquisadora do Departamento de Diagnóstico e Pesquisa Agropecuária - Secretaria da Agricultura, Pecuária e Irrigação do RS. E-mail: larissabueno@gmail.com

3 Graduado em Agronomia (UFRGS). Mestre em Agronegócios (CEPAN-UFRGS). Pesquisador do Departamento de Diagnóstico e Pesquisa Agropecuária - Secretaria da Agricultura, Pecuária e Irrigação do RS. E-mail: carlosoliveirafepagro@gmail.com
} 
sparkling, and widely used by dairy products, GI have also been used for fruits, vegetables and other fresh products. Our aim is to analyze the relationship of fruits with their territory with a background of the concept of terroir - that results from the interaction of natural and human factors in a given territory. We compared the documentation that supports the certification of four fruits, two cases in Europe and two in Brazil. We found that, in the European cases, the relationship between product and territory of origin, or terroir effect on the product, is present more fully. In Brazil cases seems to prevail the natural conditions (soil and climate, especially) as enough aspects to justify a GI. In the documentation accessed, we not realize what would be historical or cultural relationship of these products and their territories, nor the recovery of agronomic practices that may have been developed locally. We conclude by considering the importance of discussion about processes of geographical indication currently ongoing, and deepen conceptual discussion related with certification of origin.

Keywords: fruits certification, origin certification, territory.

\section{INTRODUÇÃO}

O consumo alimentar sofreu profundas mudanças nos últimos cinquenta anos. Os anos pós II Guerra Mundial foram marcados pela aceleração da industrialização, inclusive no setor de transformação alimentar, nos países ocidentais. Mudanças na vida em sociedade, a forte entrada das mulheres no mercado de trabalho, determinaram alterações e formação de novos hábitos alimentares, como a diminuição do tempo dedicado ao preparo de refeições, aumento do consumo de alimentos pré-prontos, etc.

No setor agrícola duas tendências se acentuaram nesse período: a diminuição do volume de trabalho, devido ao processo de mecanização; e o aumento da produtividade, bases do "[...] modelo agrícola de massa". Em seguida, a indústria de transformação alimentar se desenvolveu e sofisticou sua oferta, levando ao mercado produtos elaborados que seguem a norma industrial, visando um tipo de qualidade ligado à lógica de padronização, ou estandardização (ALLAIRE, 1995).

Essa tendência esteve particularmente presente em países do norte da Europa, devido, além do estabelecimento de normas sanitárias cada vez mais rígidas, a mudanças culturais, dentre as quais uma desvalorização do que podemos chamar de "cozinhas tradicionais", que resultaram em certa homogeneização da oferta alimentar (TREGEAR et al., 2007; PARROT; WILSON; MURDOCH, 2002).

Entretanto, os consumidores parecem estar modificando seus critérios de julgamento e seu nível de exigência em relação aos alimentos. Muito dessa mudança se deve a episódios de crises em termos de segurança alimentar ${ }^{4}$, para citarmos os mais emblemáticos: a epidemia da encefalite espongiforme bovina - a doença da "vaca-louca" em 1996 na Europa (e especialmente no Reino Unido); a contaminação de carne de frango por dioxina na Bélgica, em 1999; uma contaminação em grandes proporções de carne moída bovina por E. coli, nos Estados Unidos, em 2002.

\footnotetext{
${ }^{4} \mathrm{O}$ termo « segurança alimentar » é um conceito utilizado por pesquisadores da área de sanidade, mas ele está igualmente relacionado à capacidade de satisfação de exigências nutricionais mínimas diárias. Nesse caso, especificamente, nós nos referimos ao conceito sanitário, o qual entende que um alimento seguro é aquele que não oferece risco à saúde de quem o consome.
} 
No que se refere ao conteúdo simbólico, a forte industrialização do setor fez com que os alimentos perdessem sua identidade (GABRIEL; URIEN, 2006; BOTTAZZI, 1994) tornando-se, a tal ponto transformados, quase não mais reconhecíveis, que Fischler (1990) os compara a OCNI - Objetos Comestíveis Não Identificados.

Nesse contexto, a origem dos alimentos começa a se tornar um sinal de qualidade, a qual traz também em si uma promessa de "tipicidade", "[...] no sentido em que ela alude a um produto de concepção única - singular e original" ${ }^{5 "}$. E mais do que em outras áreas, no setor agroalimentar, a origem dos alimentos tornou-se cada vez mais um "[...] fator de reconhecimento e vetor de confiança junto aos consumidores, e um suporte de notoriedade e reputação para os produtores ${ }^{6,}$ (VALSESCHINI, 2000, p. 491, p. 493).

No Brasil, podemos referenciar produtos alimentares conhecidos pela sua origem, como o Queijo do Serro (MG), a Cachaça de Salinas (MG), o Abacaxi de Terra de Areia (RS). Esses produtos têm uma reputação ligada à sua origem. A maior parte deles, no entanto, não conta com uma certificação atestando essa origem, pois apenas recentemente o Brasil regulamentou esse processo. Os primeiros produtos a demandarem o selo oficial brasileiro são em grande parte bebidas (vinhos, espumantes e aguardentes), café e queijos. As Indicações Geográficas (IG) no Brasil têm sido solicitadas, entretanto, por produtos como doces, própolis e, recentemente, frutas.

Este trabalho tem como objetivo discutir a concessão de IG para frutas a partir de uma análise comparativa entre casos brasileiros e europeus, utilizando para isso revisão bibliográfica de conceitos, legislação, e de dados secundários dos processos de concessão de IG.

Inicialmente faremos uma revisão do conceito de IG, que se apoia na noção francesa de terroir, discutindo os objetivos para os quais esse instrumento foi criado na Europa. Em seguida apresentamos o marco regulatório europeu e brasileiro para comparar quatro casos de frutas com certificação de origem, um caso na França da maçã (Malus domestica L.) de Limousin, um caso em Portugal do Ananás (Ananas comosus L.) dos Açores de São Miguel e dois no Brasil: a uva (Vitis vinífera L.) de mesa e a manga (Mangifera indica L.) do Vale do Submédio São Francisco e o melão (Cucumis melo L.) de Mossoró.

\section{MATERIAL E MÉTODOS}

O presente artigo se baseia em uma análise crítica elaborada a partir de pesquisa bibliográfica junto a órgãos governamentais nacionais e internacionais relacionados ao assunto, bem como marco regulatório e legislação brasileira e europeia, documentos e sites das associações de produtores, pesquisas e artigos científicos publicados sobre o tema.

A definição dos casos estudados no Brasil se impôs pelo fato de que as duas IG abordadas eram as únicas concedidas para frutas no momento da elaboração do trabalho. Os casos europeus foram escolhidos por se basearem em variedades de frutas não nativas, introduzidas no território europeu, à semelhança dos casos brasileiros.

\footnotetext{
5 « au sens où elle concerne un produit de conception unique - singulier et original »

${ }^{6}$ « facteur de reconnaissance et vecteur de confiance auprès des consommateurs d'un côté, support de notoriété et de réputation pour les producteurs »
} 


\section{INDICAÇÕES GEOGRÁFICAS}

Embora a relação de produtos com suas regiões de origem seja tão antiga que, mesmo na bíblia, encontremos referências de produtos como os vinhos de EnGedi, e cedro do Líbano (BRUCH, 2008), contemporaneamente a IG é um conceito originalmente europeu. Ele foi desenvolvido na França a partir do início do século $X X$, quando uma crise importante da vitivinicultura fez com que fossem criadas regras para o uso de nomes geográficos (BÉRARD; MARCHENAY, 2007).

O primeiro objetivo das IG era proteger consumidores e produtores de falsificações. Os produtos com origem definida, a qual representava um diferencial em termos de reputação, beneficiavam os produtores com uma renda relacionada à qualidade. Essa produção precisava ser protegida de cópias através de uma certificação que garantisse aos consumidores sua origem, estratégia que se revelou eficaz (FOURNIER et al., 2009).

De acordo com Fournier et al. (2009), entretanto, nos países em desenvolvimento, onde o conceito de IG ainda é uma novidade, poucas são as IG que buscam proteger os produtos vítimas de falsificações no mercado local. $\mathrm{O}$ uso das IG nesses países segue um segundo objetivo relacionado a essa certificação, que é a busca de diferenciação no mercado, e por consequente, a valorização de um produto com base em uma reputação.

A IG pressupõe uma ligação do produto com seu local de origem. No entanto, mesmo a definição de IG da Organização Mundial do Comércio (OMC) parece muito vaga e abrangente: "[...] nós entendemos como indicações geográficas as indicações que servem para identificar um produto como originário do território [...], no caso em que uma qualidade, reputação ou outra característica determinada do produto possa ser atribuída essencialmente a essa origem geográfica" (GIOVANNUCCI et al., 2009, p. 6). Isso tem permitido registros sem exigência de comprovação mais detalhada. Ou seja, sem considerar a concepção original de IG, que, antes de tudo, alude a um patrimônio territorial e coletivo.

\subsection{INDICAÇÕES GEOGRÁFICAS E A NOÇÃO DE PATRIMÔNIO TERRITORIAL}

As noções de IG mobilizam relações complexas entre um produto e sua origem, delimitada em termos espaciais e históricos. $O$ produto originário desse sistema pode ser analisado como um patrimônio do local. Bérard e Marchenay (2007, p. 10) propõem dois critérios a fim de caracterizar o patrimônio em termos de oferta alimentar: a profundidade histórica e o saber-fazer compartilhado. Os autores argumentam que o saber-fazer ligado a práticas comuns, inscritas na história de um território formam uma dimensão coletiva 'ancorada' na cultura. Tal laço "[...] permite distinguir a proveniência (vir de um lugar), da origem (ser de um lugar). Por outro lado, a dimensão temporal pode variar conforme o caso, podendo ser de muitos séculos ou muitas décadas em relação à história local. A anterioridade das práticas ligadas à memória coletiva é o que confere o status particular à origem.

Essa relação complexa entre o produto e seu território alude ao que os franceses chamam de efeito terroir. Dessa forma, temos: um ambiente natural - base física das atividades, que se exprime através de produtos; e as atividades humanas - que desenvolvem saberes (savoir-faire), processos de transformação de matérias primas. Os modos de organização social e suas representações completam a

\footnotetext{
7 “[...] on entend par indications géographiques des indications qui servent à identifier un produit comme étant originaire d'un territoire [...], dans les cas où une qualité, réputation ou autre caractéristique déterminée du produit peut être attribuée essentiellement à cette origine géographique".
} 
relação do produto com o seu lugar de origem (BARJOLLE; BOISSEAUX; DUFOUR, 1998), conforme podemos visualizar na Figura 1.

Figura 1 - O terroir entre componentes humanos e físicos

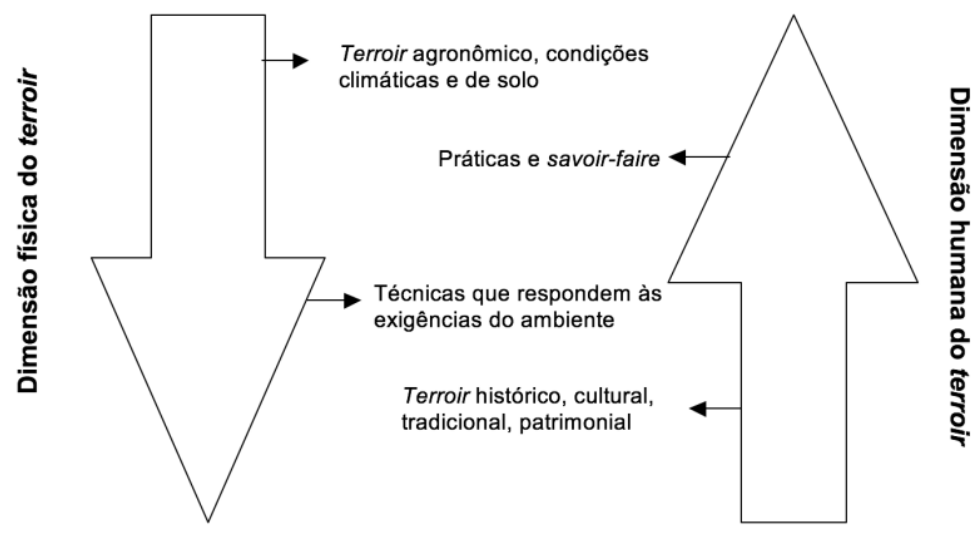

Fonte: adaptado de Barjolle et al. (1998).

Os produtos considerados como patrimônios de um território nascem dessa interação. Trata-se de produtos únicos, pois suas características são diretamente influenciadas por fatores culturais (modos de cultivo, modos de preparo e de processamento dos alimentos, receitas); e fatores ambientais (características edafoclimáticas, variedades vegetais adaptadas, raças animais adaptadas, influência do solo e clima em características do produto), tudo isso determina em maior ou menor medida o efeito terroir.

\subsection{MARCO REGULATÓRIO DE INDICAÇÕES GEOGRÁFICAS}

É preciso destacar que sistemas de certificação baseados na indicação de origem existem, por exemplo, na França desde 1919, através do sistema "Appellation d'Origine Controlée" (AOC).

O selo, ou label, AOC francês pode ser traduzido como Denominação de Origem Controlada e é definido da seguinte forma: "[...] um selo francês que designa um produto que tira sua autenticidade e sua tipicidade de sua origem geográfica. Ele é a expressão de uma ligação íntima entre o produto e seu terroir". Todo o processo de produção deve acontecer no interior da área delimitada pelo AOC, e o selo deve ser requerido por um organismo coletivo de representação (INSTITUT..., s/d).

Já o AOP (Appélation d'Origine Protégée) é a transposição para o âmbito europeu do label AOC francês para produtos derivados de leite e agroalimentares em geral, com exceção de vinhos. Para se beneficiar de um selo AOP a denominação do produto deve ter sido reconhecida como $A O C$ em seu país de origem e constar no registro das denominações de origem protegidas e indicações geográficas protegidas da Comissão Europeia (INSTITUT..., s/d). Em Portugal a tradução do AOP é Denominação de Origem Protegida (DOP), designação que utilizaremos no trabalho.

\footnotetext{
${ }^{8}[\ldots]$ est un signe français qui désigne un produit qui tire son authenticité et sa typicité de son origine géographique. Elle est l'expression d'un lien intime entre le produit et son terroir".
} 
O selo IGP é de âmbito europeu (Indication Géographique Protégée, traduzido como Indicação Geográfica Protegida), e distingue um produto onde nem todas as fases de produção acontecem na zona geográfica delimitada, mas que se beneficia de uma relação com o território e de uma notoriedade. A relação entre o produto e sua origem, nesse caso, é menos forte do que na DOP-AOC, entretanto ela é suficiente para conferir uma característica ou reputação a um produto (INSTITUT..., s/d).

Cada país determina um organismo responsável por receber os pedidos de registro, tendo procedimentos equivalentes para tramitação e homologação. Todo o processo é regulado pela Direção Geral da Agricultura e Desenvolvimento Rural da Comissão Europeia. Na França o organismo que recebe as demandas, não apenas de indicações geográficas (IGP e DOP), mas também de outras certificações, como Agriculture biologique e Label rouge, é o Institut National de l'Origine et de la Qualité (INAO - na tradução: Instituto Nacional da Origem e da Qualidade, subordinado ao Ministério da Agricultura). O INAO tem papel ativo no fomento e proteção das IG, pois, além de receber e analisar os pedidos, seu escopo de atuação tem por objetivo preservar as condições de produção nas áreas com IG. Por exemplo, o INAO deve ser consultado a respeito de projetos de desenvolvimento, urbanização ou obras dentro de zonas que utilizam alguma certificação de origem, pois faz parte de sua missão "[...] preservar uma agricultura de qualidade e os territórios rurais produtivos e vivos" (INSTITUT..., s/d).

No Brasil o marco regulatório para a IG é a Lei Nacional n.ำ 9.279, de 14 de maio de 1996. A legislação, através do seu artigo 176, não define o que é Indicação Geográfica, estabelece apenas suas espécies: a Indicação de Procedência e a Denominação de Origem.

O artigo 177 da mesma lei define Indicação de Procedência (IP), como "[...] o nome geográfico de país, cidade, região ou localidade de seu território, que se tenha tornado conhecido como centro de extração, produção ou fabricação de determinado produto ou de prestação de determinado serviço" (BRASIL, 1996).

A denominação de origem (DO) é definida pelo artigo 178, "é considerado o nome geográfico de país, cidade, região ou localidade de seu território, que designe produto ou serviço cujas qualidades ou características se devam exclusiva ou essencialmente ao meio geográfico, incluídos fatores naturais e humanos" (BRASIL, 1996).

Quem regula a concessão e recebe os pedidos de reconhecimento é o INPI - Instituto Nacional de Propriedade Industrial, subordinado ao Ministério do Desenvolvimento, Indústria e Comércio Exterior, que conceitua Indicação Geográfica como:

[...] a identificação de um produto ou serviço como originário de um local, região ou país, quando determinada reputação, característica e/ou qualidade possam ser vinculadas essencialmente a esta sua origem particular. Em suma, é uma garantia quanto à origem de um produto e/ou suas qualidades e características regionais (BRASIL, 1996).

A relação estabelecida a partir da DO entre produto e origem é mais complexa, e, segundo o INPI (2010),

[...] deve afetar o resultado final do produto ou a prestação do serviço, de forma identificável e mensurável, o que será objeto de prova quando formulado um pedido de registro [...], através de estudos técnicos e científicos, constituindo-se em uma 
prova mais complexa do que a exigida para as Indicações de Procedência (BRASIL, 1996).

Uma particularidade importante do Brasil é que, além de produtos agroalimentares e alimentos, produtos não agrícolas e, mesmo, serviços podem obter uma IG, diferentemente da Europa. O Brasil conta até o presente momento com 46 processos aprovados de IG, desses 32 são concernentes a produtos alimentares, 13 são produtos não alimentares, e 1 se refere a serviços. Dentre essas 46 IG, 16 são DO - dessas, 8 são estrangeiras, e 30 são IP. Duas das Indicações de Procedência registradas no INPI foram concedidas para frutas: Mossoró, para o melão; e Vale do Submédio São Francisco, para uvas de mesa e manga.

Analisando as definições, podemos inferir que a DO brasileiro seria equivalente a DOP europeia, ambas fazendo referência ao diferencial do produto devido aos efeitos geográficos de sua localização, seja por aspectos naturais ou humanos (efeito terroir). O conceito de IP seria o equivalente a IGP, onde a relação entre produto e território de origem é menos forte, a definição brasileira, no entanto, é bastante vaga.

\section{A INDICAÇÃO GEOGRÁFICA PARA FRUTAS}

A IG, por estabelecer um atestado de determinada reputação, característica e/ou qualidade vinculada essencialmente à origem particular das frutas, pode favorecer a inserção destes alimentos em mercados mais exigentes e que remuneram melhor. A certificação pode também impactar positivamente na organização da cadeia produtiva no local de origem do produto e operar como um instrumento de proteção para os produtores, através de mecanismos legais de combate ao uso irregular da reputação da origem das frutas.

\subsection{CASOS EUROPEUS DE INDICAÇÃO GEOGRÁFICA DE FRUTAS}

$\mathrm{Na}$ Europa há uma gama de frutas in natura com registro de indicação geográfica. Nosso artigo abordará dois casos em particular, o primeiro na França e o segundo na llha dos Açores, em Portugal.

A maçã da região do Limousin na França se beneficia de uma DOP desde 2007, assim o produto é chamado "Pomme du Limousin AOP". O produto já tinha o reconhecimento através do equivalente francês AOC desde 2005. Para portar a IG para a qual foi habilitado, o fruto deve ser cultivado em uma área geográfica delimitada (ver Figura 2), com um sistema de cultivo descrito em um caderno de normas (cahier de charges), e a partir da variedade Golden Delicious (INSTITUT..., 2012). Importa salientar que a variedade em questão tem origem nos Estados Unidos, não sendo, portanto, nativa da região do Limousin. O cultivo de maçã, entretanto, está presente no território desde a antiguidade: os romanos teriam implantado os primeiros pomares com mudas provenientes do Oriente Médio. Desde então, os pomares se desenvolveram, e a partir do século XVIII a reputação da maçã do Limousin já chegava a Paris.

O documento de registro da IG "Pomme du Limousin" no INAO mostra como a localização é determinante nas características finais do produto, pois as condições de clima e relevo favoreceram historicamente o desenvolvimento de saberes relacionados ao cultivo da maçã na região. Assim, se, ao longo do tempo muitas variedades locais foram desaparecendo e sendo substituídas por novas, no entanto, o conhecimento desenvolvido para o cultivo das macieiras perdurou e, juntamente com os fatores naturais já citados, conferem o efeito do terroir sobre a 
variedade que foi implementada a partir dos anos 1950 na região (INSTITUT..., 2012).

Figura 2 - Região do Limousin na França, onde se encontra a DOP da maçã

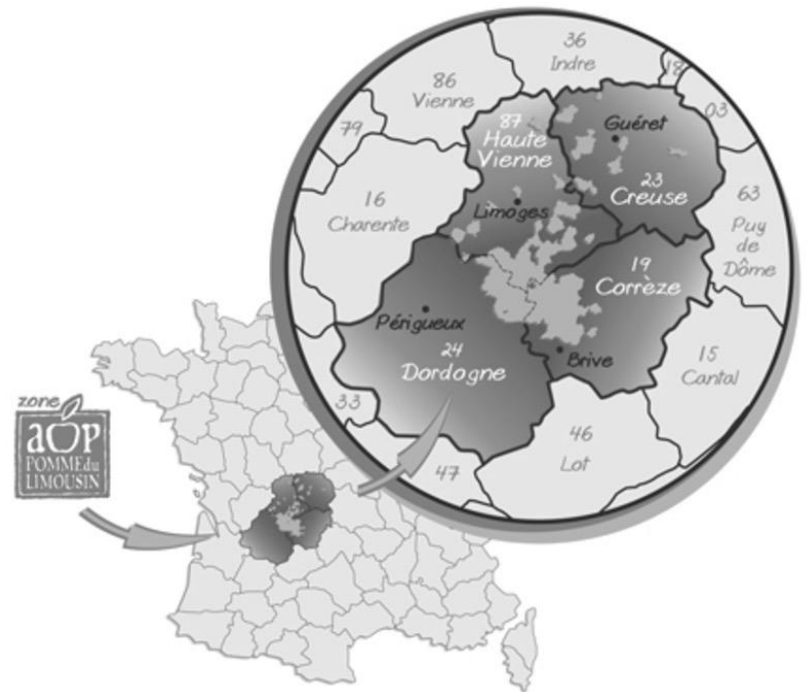

Fonte: Association Pomme du Limousin, (2008).

Para requerer o label "Pomme du Limousin - $A O P$ " foi necessário estabelecer o histórico de cultivo do produto e sua relação com o território, delimitar a área de produção caracterizando também os efeitos do clima e relevo sobre o produto, descrever o produto e suas características. Também foi necessário estabelecer um "Caderno de normas" que deve ser seguido pelos produtores da região delimitada, o que Ihes conferirá o direito de portar a IG nos seus frutos. Fol preciso, além disso, prever um organismo de controle para verificar o seguimento das normas estabelecidas que preveem, desde o modo de produção (que determina uma densidade máxima dos pomares de 1000 a 3000 árvores/ha, poda a cada dois anos, produtividade máxima de 58 t/ha, restrições ao uso de irrigação, entre outras), a variedade permitida, o estabelecimento da época da colheita (início autorizado através de portaria regional) e forma (apenas colheita manual é permitida), as regras de estocagem, acondicionamento e etiquetagem (cada fruta deve ser identificada com uma etiqueta onde consta "Pomme du Limousin" e a menção "Appélation d'origine protegée" ou "AOP"), (INSTITUT..., 2012). O grupo demandante no processo foi uma associação, o Syndicat de défense de l'AOP Pomme du Limousin', já que a legislação europeia prevê que as IG são um bem coletivo, que não podem ser geridas por empresas ou pessoas físicas.

\footnotetext{
${ }^{9}$ Há 289 propriedades cultivando maçã na região de Limousin, dessas 218 produzem o fruto certificado AOC e são ligadas ao Syndicat de défense de l'AOC Pomme du Limousin. Isto representa $75 \%$ dos produtores e $87 \%$ da superfície de produção. Uma produção média de 90 mil toneladas por ano, desse volume $15 \%$ portam o selo AOP. A produção certificada tem crescido, de 7.800 toneladas para 13.500 entre 2010 e 2015 . Os frutos que portam o selo AOP obtém uma valorização de cerca de $25 \%$ no mercado.
} 
Entre as mais de mil designações de origem que são estimadas como protegidas no âmbito da União Europeia, Portugal representa cento e vinte produtos registrados, dos quais 21 são frutas, o que representa 18\% (TIBERIO; FRANCISCO, 2012).

O segundo caso analisado em nosso trabalho é o do Ananás dos Açores da Ilha de São Miguel em Portugal, que possui DOP desde 1996. Como no caso da maçã de Limousin, o fruto não é nativo, tendo sido introduzido na região pelos portugueses entre os séculos XVII e XVIII, que trouxeram o ananás do Brasil. Na época, o ananás foi cultivado em estufas como cultura experimental e curiosidade botânica ornamental. A partir do final do século XIX, o ananás passa a ser encarado como um produto capaz de contribuir para o desenvolvimento da economia açoriana. Segundo consta no caderno de especificações da DOP do Ananás, a primeira estufa destinada a produção em maior escala foi construída em 1864.

Segundo o caderno de normas do produto, o ananás

[...] é produzido exclusivamente em estufas de vidros, com recurso a técnicas e práticas culturais seculares, o Ananás dos Açores/São Miguel distingue-se dos seus similares produzidos ao ar livre noutras regiões. A proteção destas características [...] constitui preocupação de há longa data, citando-se a título de exemplo, a legislação portuguesa mais antiga, designadamente o Decreto $\mathrm{n}^{\circ} 24.581$ de 20 de outubro de 1934 onde já se pretendia preservar a produção de ananás na llha de São Miguel, criando essencialmente mecanismos necessários para proteger os métodos tradicionais utilizados (DIREÇÃO..., 1994).

A conservação do conhecimento tradicional no modo de produzir o ananás dos Açores destaca a importância dos saberes (savoir-faire) no cultivo, os quais vem sendo repassados entre as gerações de produtores. As técnicas tradicionais, como a utilização de 'camas quentes' e o cultivo em estufas de vidros, permitiram que o fruto tropical estivesse acessível nos países europeus por dezenas de anos (SANTOS, 2010).

Para portar a IG para a qual foi habilitado, o fruto deve ser cultivado na llha de São Miguel, com um sistema de cultivo descrito no caderno de especificações da DOP "Ananás dos Açores/São Miguel", a partir da variedade Cayene "folhas lisas", em estufas de vidro de até 175 metros. O caderno de especificações ressalta o aspecto histórico da produção de ananás nos Açores, assim como estabelece parâmetros qualitativos para a polpa do ananás, estágio de maturação, tamanhos de frutos, formas de acondicionamento (caixas de madeira, papelão ou plástico), além de rotulagem com a menção "Ananás dos Açores/São Miguel" - Denominação de Origem. Consta no caderno de normas também o organismo certificador, sendo a entidade demandante da IG a Profrutos - Cooperativa de Produtores de Frutas, Produtos Hortícolas e Florícolas de São Miguel $^{10}$. Na figura 3, destaca-se a localização da região de produção.

\footnotetext{
${ }^{10}$ Constituída em 1972 por 33 associados, fruto da necessidade de criar um organismo que estivesse mais próximo do produtor, a Profrutos - Cooperativa de Produtores de Frutas, Produtos Hortícolas e Florícolas de São Miguel tem como principal atividade a comercialização de Ananás dos Açores/S. Miguel, detendo uma quota de produção de 68\%. A Profrutos conta atualmente com 207 associados, 173 dos quais produtores de Ananás dos Açores, somando 1.353 estufas que perfazem uma área de produção de 34 hectares (segundo dados de 2012), tendo alcançado em 2013 uma produção de 522 toneladas.
} 
Figura 3 - Região da llha de São Miguel em Portugal.

Ananás dos Açores / São Miguel DOP
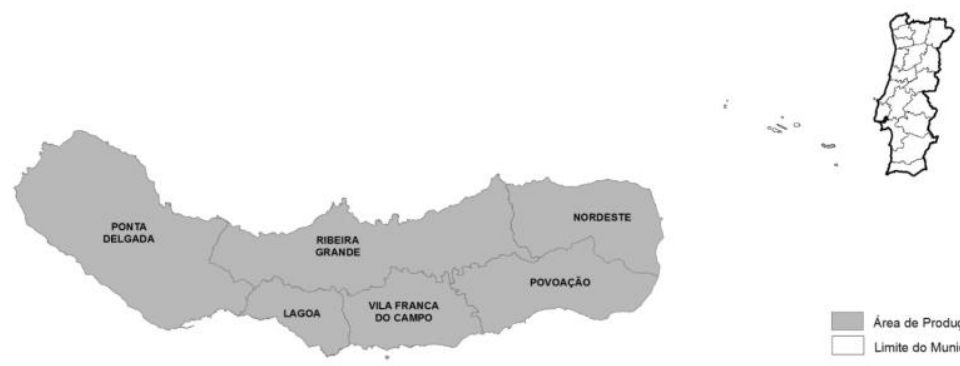

Fonte: Carta Administrativa Oficial de Portugal da DGT, 2013.

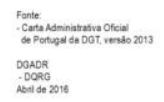

Os dois casos abordados demonstram que o processo de obtenção de uma IG para frutos nos países membros da UE segue a lógica de garantir as características ou qualidades que fazem a reputação de um produto, ou seja, o efeito do terroir, e, para beneficiar-se da IG é preciso estabelecer e seguir os métodos de produção determinados. Esses métodos são a expressão da dimensão cultural e histórica desse terroir.

\subsection{CASOS BRASILEIROS DE INDICAÇÃO GEOGRÁFICA DE FRUTAS}

No Brasil, as IG para frutas "in natura" são recentes. A primeira IG para frutas foi concedida em 2009, como indicação de procedência para o "Vale do Submédio São Francisco" para uva de mesa e manga, cuja área geográfica delimitada abrange $125.755 \mathrm{~km}$ do semiárido nordestino a oeste de Pernambuco e norte da Bahia, figura 4. 
Figura 4 - Localização do Vale do Submédio São Francisco.

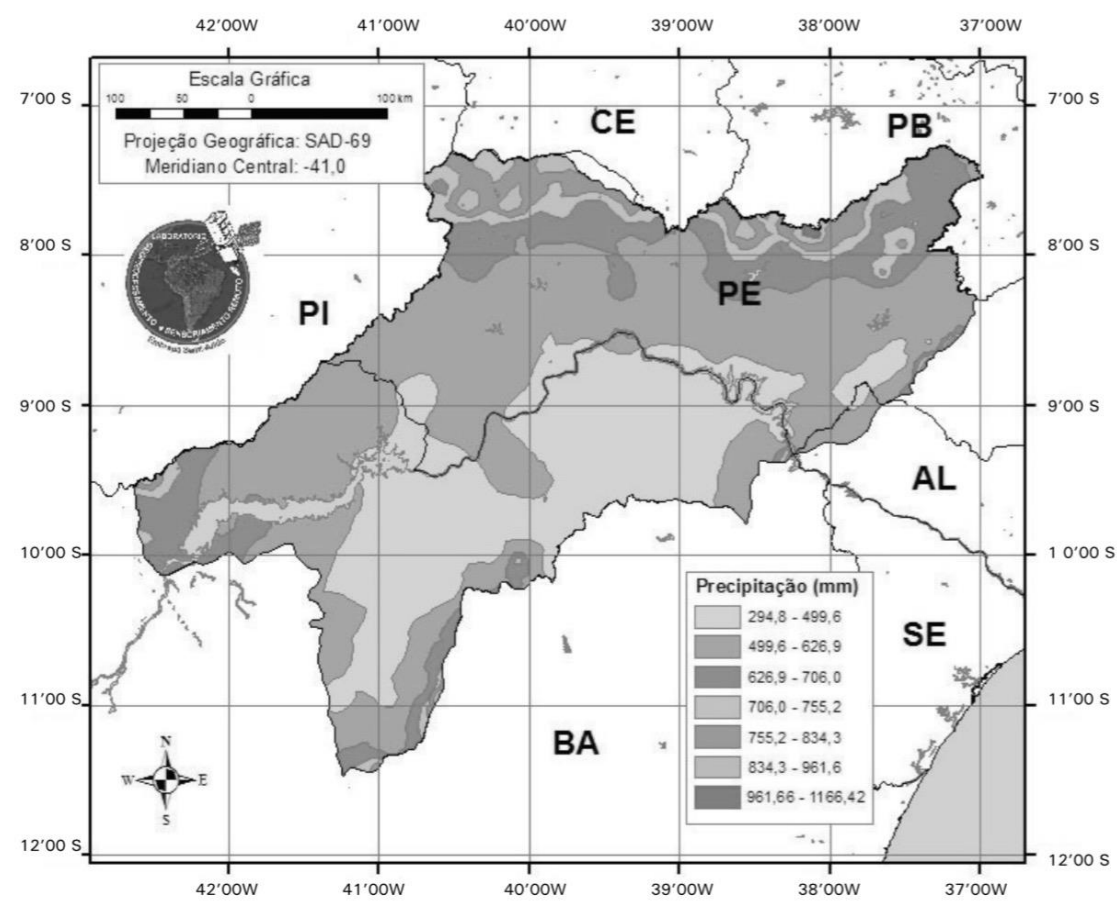

Fonte: Lima et al. 2009.

Em 2013, o registro de Indicação de Procedência foi concedido para o melão produzido em Mossoró, no Rio Grande do Norte.

O Vale do Submédio São Francisco está entre os principais polos de viticultura tropical no Brasil, juntamente com o noroeste Paulista e o norte de Minas Gerais. Antes de obter a indicação de procedência, o Vale do Submédio São Francisco obteve, em 2003, a certificação do programa de Produção Integrada (PI) de Uva. O sistema de Produção Integrada reúne normativas e procedimentos que asseguram a qualidade da fruta, a aplicação de procedimentos técnicos coerentes com o respeito ao ambiente, à legislação trabalhista e à saúde do consumidor (CAMARGO; TONIETO; HOFFMANN, 2011). Entre os efeitos da adesão à PI, desenvolveram-se iniciativas de busca a outros protocolos privados de certificação de qualidade para atendimento de mercados específicos, como é o caso do sistema de Análise de Perigos e Pontos Críticos de Controle (APPCC) e da GLOBALGAP, e, por fim, a Indicação de Procedência para uvas de mesa e para a manga.

A concessão de indicação de procedência para duas frutas em conjunto e delimitando um território de produção de dois estados da região Nordeste do Brasil (Pernambuco e Bahia) foi entendida como ação de fomento ao desenvolvimento regional (LIMA, 2009).

A dimensão física do terroir é preponderante na qualificação dos frutos com indicação de procedência do Vale do Submédio São Francisco. Destacam-se os seguintes aspectos: a alta quantidade de radiação solar, o alto número de horas de insolação, as altas temperaturas e a baixa umidade relativa do ar, que, ao longo do 
ano, favorecem uma maior atividade metabólica, permitindo produções mais precoces em relação à maioria das regiões produtoras. As condições climáticas também favorecem o maior acúmulo de sólidos solúveis nos frutos, na forma de açúcares, e rápida degradação de ácidos orgânicos, conferindo um sabor doce aos frutos maduros, o que favorece a apresentação dos produtos para consumo in natura.

A entidade demandante do registro foi a União das Associações e Cooperativas dos Produtores de Uvas de Mesa e Mangas do Vale do Submédio São Francisco (Univale) ${ }^{11}$.

Outro estado do Nordeste que obteve certificação de origem para frutas fol o Rio Grande do Norte. O estado é o maior produtor e exportador de melão do Brasil, sendo o produto o primeiro item da pauta de exportações do RN (ARAÚJO, 2011). São cultivados mais de 8 mil hectares, que geram 250 mil toneladas de melão por safra.

O registro de Indicação de Procedência do melão de "Mossoró" foi concedido em 2013. A área de produção delimitada abrange os municípios de Afonso Bezerra, Alto do Rodrigues, Areia Branca, Assu, Baraúna, Carnaubais, Grossos, Ipanguaçu, Mossoró, Porto do Mangue, Serra do Mel, Tibau e Upanema (INPI, 2013), ver figura 5. Assim como no caso do Vale do Submédio São Francisco o clima e o solo da região de Mossoró favorecem o cultivo de melões, formando uma reputação de qualidade reconhecida interna e externamente ao país.

Figura 5 - Mapa do estado do Rio Grande do Norte com delimitação de regiões e nomes de municípios selecionados

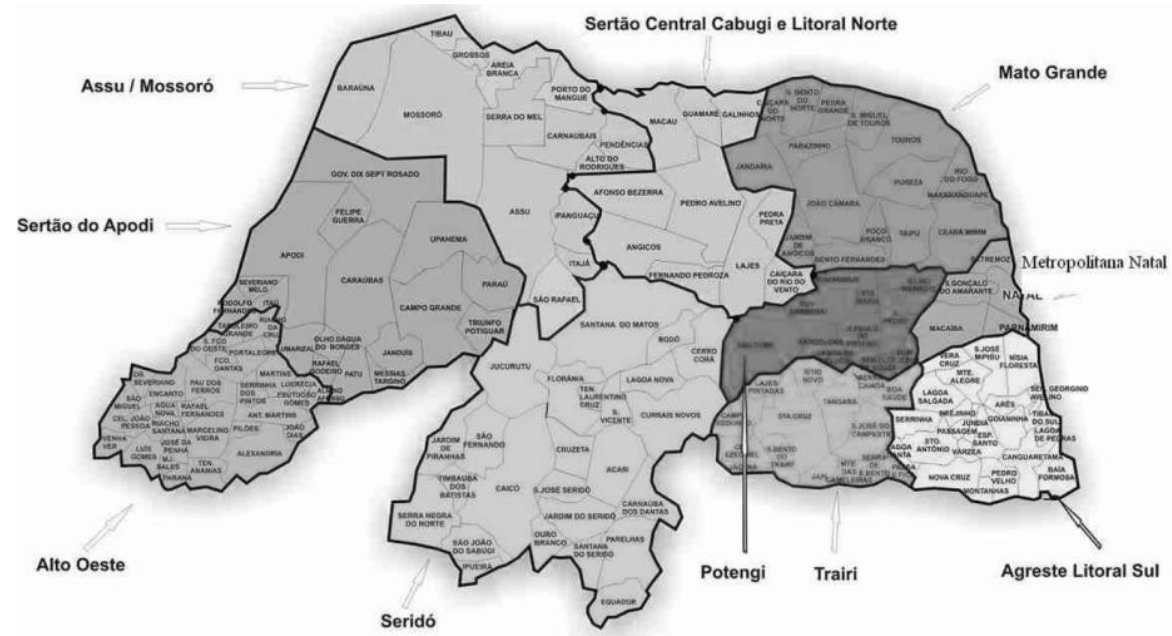

Fonte: Guia de Turismo e Viagem Salvador, Bahia e Nordeste, 2017.

A dimensão física do terroir proporciona frutas consideradas doces e com boa durabilidade pós-colheita. Também desde 1990 a região de Mossoró é reconhecida pelo Ministério da Agricultura Pecuária e Abastecimento como área livre de mosca-das-frutas, inseto que pode se tornar praga colocando seus ovos no

\footnotetext{
${ }^{11}$ A Univale compreende um conjunto de 12 associações e cooperativas que congregam em torno de 342 produtores de manga e de uva de mesa de Petrolina (PE) e Juazeiro (BA).
} 
interior dos frutos. O status de livre de mosca das frutas favorece a exportação dos melões para países da Europa, para o Japão e para os Estados Unidos. Atualmente, do total produzido, $64 \%$ são exportados, principalmente para Inglaterra, Holanda, Bélgica, França, Dinamarca, Alemanha, Irlanda, Islândia e Espanha. Estes mercados reconhecem e valorizam os produtos com IG.

No caso do melão há também uma preocupação com o uso indevido da origem Mossoró por produtos não originários da zona geográfica abrangida. O demandante da IG Mossoró para melões foi o Comitê Executivo de fruticultura do $\mathrm{RN}^{12}$.

Salientamos que, para concessão de IP, o INPI não exige e, portanto, não há em nenhum dos casos, registro de um caderno de normas a ser seguido no que se refere ao cultivo, estocagem e comercialização.

\section{DISCUSSÃO}

A análise comparativa dos casos de certificação de origem de frutas no Brasil e na Europa fornece elementos de contraste. Primeiramente, nos casos brasileiros, a documentação indica uma frágil ancoragem do produto com relação a seu território de origem.

Nos casos da maçã do Limousin e do Ananás dos Açores/São Miguel, a documentação enfatiza o aspecto patrimonial do fruto, no sentido de que as culturas fazem parte da história local há pelo menos alguns séculos. Além disso, é possível encontrar nos registros de ambos, como o resultado da interação fruto, meio ambiente e manejo afetam o produto final e fazem desses frutos produtos singulares. Por esse motivo, os cadernos de normas são bastante detalhados, e os frutos que portam a indicação devem seguir estritamente o que está estabelecido na documentação em termos de variedade e manejo.

Nos casos brasileiros, a documentação é mais restrita, não sendo possível localizar temporalmente o início das culturas e sua relação com a história local. Evidentemente os frutos brasileiros tem uma história mais recente, o que em si não constitui um problema, mas o fato de não haver nenhuma menção a esse registro, nem sobre o papel das culturas frutíferas na economia local é que nos parece frustrante.

Ainda que os frutos brasileiros portem IP e não DO, a interação fruto, meio ambiente e manejo também é descrita de forma superficial. Não há indicação sobre o manejo a ser utilizado para que os frutos tenham direito de utilizar o selo. A relação das frutas certificadas com as práticas e o savoir-faire necessários à condução da atividade, seu enlace com a cultura e história do território delimitado, ou seja, as dimensões humanas do terroir, permanecem desconhecidas para o leitor dessa documentação.

Nos casos europeus há uma série de elementos nos cadernos de normas, como a determinação das épocas de colheita e plantio, a densidade dos pomares ou frutos, a determinação do padrão das estufas para o Ananás, a restrição ao uso de irrigação para as maçãs do Limousin, entre outros já descritos. Cabe ressaltar que a legislação brasileira para a concessão de IP desobriga essa necessidade, no entanto, outros estudos que abordam IG brasileiras também salientam uma carência nos critérios de análise de elementos como saberes e conhecimentos, inserção histórica e cultural, o que pode ter como consequência a perda gradual de práticas e

\footnotetext{
12 O Comitê congrega mais de 40 grupos associados de produtores de frutas, desses, 12 utilizam a IG do Melão de Mossoró.
} 
receitas que fazem parte do patrimônio gastronômico e cultural do país (BRANCO et al., 2013; SANTOS, 2014; BELLAS; WILKINSON, 2014).

Segundo Matos e La Rovere (2017), há uma falta de clareza na utilização de alguns conceitos normativos, apesar da legislação brasileira datar de quase 20 anos. As autoras demonstram que há uma certa falta de alinhamento entre o arcabouço normativo brasileiro com relação ao europeu, especialmente no que se refere ao reconhecimento da dimensão histórica e cultural, e uma ausência de critérios para analisar a importância do fator humano nos processos de reconhecimento de IG no Brasil. Outro problema apontado pelas autoras é que a novidade do tema para as instituições brasileiras envolvidas em processos de fomento a IG leva a diferentes interpretações de alguns conceitos. Destaca-se, portanto, a necessidade de aprofundar o debate conceitual que embasa a iniciativa no país

Outro aspecto referente às frutas certificadas no Brasil, que difere dos exemplos europeus apresentados, é a falta de indicação sobre a variedade vegetal apta a ser certificada. No caso dos melões, podem ser do tipo galha, amarelo, pele de sapo, nap melow, ou seja, diversos grupos varietais. No caso da manga, a variedade Tommy Atkins responde por $90 \%$ da produção, mas outras variedades estão aptas à certificação. No caso da uva são adotadas variedades sem e com sementes. Isso demonstra que as IG frutíferas brasileiras não têm considerado também o fator 'interação ambiente-variedade' de forma mais detida. Ilustração disso é o relatório contendo subsídios técnicos elaborado para solicitação de IP para uva de mesa e manga do Vale do Submédio São Francisco, mencionando a condição climática da região: "[...] a resposta é observada em uva e em manga, assim como em outras frutas exploradas na região, conferindo-lhes características diferenciais" (LIMA, 2009, p. 19). O relatório não especifica essas características diferenciais e deixa a entender que outras frutas, além da manga e da uva, podem apresentar potencial para fazer uso de tal IG.

Podemos perceber, a partir da documentação analisada, que os processos de registro de IG frutíferas brasileiras e europeias não apresentam equivalência. Embora o papel dos atores sociais seja semelhante: a IG deve ser demandada por uma entidade coletiva, que representa os produtores e arca com os custos do processo, e sua concessão passa por um órgão público.

Além das diferenças objetivas evidenciadas pela documentação analisada, salientamos o contraste em relação à finalidade de tal instrumento de certificação, um debate pouco presente no Brasil ainda. Afinal, quais objetivos visa atingir o marco legal sobre IG no país: proteger denominações de produtos brasileiros no exterior, ampliar mercados externos, fomentar políticas de sustentabilidade ambiental e social em regiões rurais menos favorecidas?

Os exemplos brasileiros abordados no trabalho demonstram que as iniciativas para obtenção de IG visam mais a uma valorização dos produtos e a abertura e conquista de novos mercados. Os dois mercados internacionais mais exigentes atualmente são Estados Unidos (EUA) e União Europeia (UE), são os mercados que possibilitam também maior valorização da oferta através da IG, por fim, cada um deles possui sistemas de proteção distintos, ou que evoluíram de maneiras diferentes.

Nos Estados Unidos as IG foram incluídas na legislação existente em matéria de propriedade intelectual: a legislação sobre marcas. O sistema europeu é fundado sobre uma proteção pública, é considerado burocrático, mas aborda as IG como um bem coletivo. A UE possui uma legislação e uma série de regulamentações específicas, que dispõem exclusivamente sobre IG. 
No sistema norte-americano prevalece uma proteção que repousa sobre o direito de marcas, que pode ser considerado mais acessível e dinâmico. A ênfase nesse caso é dada ao produto, e sua utilização se dá como ferramenta de comercialização que permite recompensar os produtores e os produtos de qualidade. Uma boa reputação e uma relação clara entre origem e produto são requisitos que devem ser provados para que uma marca de certificação, equivalente a uma IG, seja concedida nos EUA (GIOVANNUCCI et al., 2009).

Já os países membros da UE consideram as IG como um sinal de qualidade e um meio de preservar regiões agrícolas tradicionais, bem como suas matérias primas e seus modos produção, em consonância com o conceito de terroir. A valorização dos produtos passa, dessa forma, por priorizar a qualidade em detrimento da quantidade, e sinalizar isso de forma clara aos consumidores através de um selo padrão (GIOVANNUCCl et al., 2009).

Por esse motivo, na Europa as IG são vistas como um instrumento de desenvolvimento para zonas rurais (BARHAM, 2003; SANZ-CAÑADA; VÁSQUEZ, 2005; LINK; LÓPEZ; CASABIANCA, 2006, TREGEAR et al., 2007). As expectativas quanto aos impactos positivos gerados por esse processo abarcam diferentes dimensões, desde aspectos econômicos (acesso a novos mercados internos e mercados externos - exportação); sociais e culturais (inserção de produtores ou regiões desfavorecidas); e ambientais (preservação da biodiversidade, dos recursos genéticos locais e do meio ambiente) (CERDAN, 2010; MASCARENHAS, 2010).

É preciso destacar que A IG, como instrumento de política pública, ganhou importância em âmbito europeu a partir dos anos 1990, com a consolidação de uma política de desenvolvimento diferenciada da PAC (Política Agrícola Comunitária), através da implementação do Programa LEADER (corresponde à sigla, em francês "Liaisons entre activités de Developement de L'Economie Rural').

\begin{abstract}
A geração de empregos, o incentivo à inovação e resgate de saberes figuram como elementos de destaque no balanço sobre os êxitos das iniciativas Leader. E é justamente nesse contexto que ganha relevo a estratégia de fortalecimento dos produtos com identidade cultural, como é precisamente o caso das indicações geográficas em toda sua riqueza e diversidade, assim como das especialidades regionais (ANJOS et al., 2014).
\end{abstract}

No entendimento de Anjos et al. (2014) e Barbosa (2015), a concepção que inspira os processos de reconhecimento de IG no Brasil parece estar mais alinhado à ênfase de uma lógica setorial.

Em nosso estudo, os dados analisados pelas IG brasileiras corroboram a percepção dos autores. Através deles, não é possível determinar a relação entre as cadeias em questão, a história e a economia local, nem antever eventuais externalidades positivas e sinergias com outras atividades econômicas locais. Processos de desenvolvimento territorial, de acordo com Fialho e Waquil (2008), devem levar em conta o conhecimento acerca da realidade, o reconhecimento e a valorização do agricultor, bem como suas motivações para processos de inovação tecnológica e social. Além disso, o território deve ter um papel ativo, funcionando como lócus para o planejamento de políticas públicas e onde ocorre a articulação dos diferentes atores: sociais, econômicos e institucionais (FREITAS; FREITAS, 2016).

A questão, entretanto, não está em julgar se o processo pode ser indutor de desenvolvimento, mas de questionar se a certificação de origem é a melhor ferramenta para o objetivo dos atores. Entendemos que a expansão e evolução das 
cadeias de frutas, seguindo uma lógica setorial, pode trazer benefícios e dinamizar a economia local. Nossa reflexão é sobre a ferramenta - seria a IG a mais adequada? - já que as iniciativas brasileiras parecem não aprofundar a ancoragem produtoorigem, que é o leitmotiv mesmo do instrumento, tal como os casos europeus.

\section{CONSIDERAÇÕES FINAIS}

Sobre a regulamentação no Brasil, pudemos constatar que (i) o conceito de Indicação de Procedência, bem como o de Denominação de Origem, foram 'importados' da UE; (ii) as IG brasileiras se aproximariam do modelo europeu também pela necessidade de sua concessão ser mediada por associações de produtores; (iii) em que pese o fato de o processo normativo estar fundamentado na Lei Nacional n. 9.279 (Brasil, 1996), o arcabouço teórico sobre o qual repousam esses conceitos parece ainda frágil, havendo pouca clareza nas definições brasileiras; (iv) o organismo gestor das IG no Brasil é o Instituto Nacional de Propriedade Industrial; (v) para concessão de IP não há exigência de um caderno de normas de produção, nem a previsão de certificação por uma terceira parte.

Entretanto, mais importante que a normatização é termos clareza de que a proteção de uma IG não se limita a seu aspecto jurídico, para garantir a eficiência do instrumento é preciso lembrar que existe uma ligação direta entre o produto, seu local de origem e sua qualidade. Para que a IG cumpra seu objetivo de longo prazo, essa ligação deve ser preservada através de toda a cadeia de produção e comercialização.

No Brasil, o debate deve ser ainda aprofundado para que possamos definir quais são as prioridades da regulamentação das denominações de origem. A partir de então, pode-se trabalhar com uma equivalência mínima, a fim de legitimar o processo internamente, mas também externamente. Insistimos na questão da equivalência pois ela pode se tornar um empecilho na medida que barreiras não tarifárias vem ganhando força para impedir a importação de produtos brasileiros em mercados como o europeu e o americano.

O debate sobre a pertinência da IG também deve levar em conta os objetivos dos atores, pois o uso de um instrumento inadequado pode frustrar os envolvidos e descreditar a IG. Se a IG é constituída para atender interesses de cadeias produtivas, ou atores isolados, visando dinamizar exportações e proteger os interesses de grupos de produtores, sem reforçar os processos de desenvolvimento territorial, ela não atenderá aos objetivos para os quais foi concebida, e poderá não envolver os atores territoriais de forma durável e sustentável.

Para concluir, esperamos ter contribuído para o debate em torno das IG no Brasil. Sabemos que falta de clareza dos órgãos reguladores não é um problema apenas brasileiro, outros países da América Latina também passam pelo mesmo problema (CHAMPREDONDE, 2013). No entanto, a falta de reflexão dos rumos e objetivos das IG no Brasil pode ter como consequências negativas: (i) 0 desconhecimento e não valorização por parte dos consumidores sobre as IG, (ii) resultados que não condizem com as expectativas daqueles que investiram no processo de certificação, gerando desconfiança e desinteresse por parte dos próprios produtores envolvidos no processo, (iii) o não reconhecimento por parte de parceiros comerciais devido à falta de equivalência dos processos de registros.

\section{AGRADECIMENTOS}

Aos pareceristas anônimos, que avaliaram o presente trabalho para a publicação, seus apontamentos e sugestões contribuíram de forma relevante para aprimorá-lo. 


\section{REFERÊNCIAS}

ALLAIRE, G. De la productivité à la qualité, transformation des conventions et régulations dans l'agriculture et l'agro-alimentaire. In : ALLAIRE, G.; BOYER, R. La grande transformation de l'agriculture. Paris: INRA-Economica, 1995.

ANJOS, F. S. et al. São as indicações geográficas um instrumento para o desenvolvimento dos territórios? Estudo de caso sobre duas experiências no estado do Rio Grande do Sul. Política \& Sociedade, v. 13, n. 26, p. 163-193, 2014.

ARAUJO, V. F. S; CAMPOS, D. F. A Cadeia Logística do Melão Produzido no Agropolo Fruticultor Mossoró/Açu. Documentos Técnico-científicos do Banco do Nordeste, v. 42, n. 3, p. 505-30, 2011.

BARBOSA, P. M. S. Marcas, indicações geográficas, selos e certificações de rastreabilidade em busca da certeza da origem e do conteúdo: o caso do café da região do Cerrado Mineiro. 2015. Tese (Doutorado em Biotecnologia Vegetal) Programa de Pós-Graduação em Biotecnologia Vegetal, Inovação e Gestão Estratégica em Biotecnologia, Universidade Federal do Rio de Janeiro.

BARHAM, E. Translation terroir: the global challenge of French AOC labeling. Journal of Rural Studies, v. 19, n. 1, p. 127-138, 2003.

BARJOLLE, D.; BOISSEAUX, S.; DUFOUR, M. Le lien au terroir: bilan des travaux de recherche de l'Institut d'économie rurale (ETHZ), 1998. Disponível em: http://www.aoc-igp.ch/files/upload/Lien\%20\%20terroir.pdf. Acesso em: 20 jul. 2016.

BELAS, C. A.; WILKINSON, J. Indicações geográficas e a valorização comercial do artesanato em Capim-dourado no Jalapão. Sustentabilidade em Debate, v. 5, n. 3, p. 56-78, 2014.

BERARD, L.; MARCHENAY, P. Produits de terroir - comprendre et agir. Bourg-enBresse: CNRS, 2007.

BOTTAZZI, G. Le développement local ou la remontée du 'local' - Considérations pour une définition de l'espace local? In : Colloque nouveaux dynamismes industriels et economie du developpement, 1994, Grenoble, França. Anais... Grenoble: Institut de recherche économique sur la production et le développement - IREPD, 1994, p. 423-447.

BRANCO, N. P. N. C. S. et al. Indicações Geográficas (IG) como ferramenta para desenvolvimento regional: uma prospecção tecnológica sobre IG relacionadas à farinha e mandioca; e o potencial da IG da farinha de mandioca Copioba do Recôncavo Baiano. In: Simpósio internacional de inovação tecnológica, 2013, Aracaju, SE. Anais... Aracaju: SIMTEC, 2013. p. 771-786.

BRASIL. Lei n. 9.279, de 14 de maio de 1996. Diário Oficial [da] República Federativa do Brasil, Poder Executivo, Brasília, DF, 14 maio 1996.

BRUCH, K. L. Indicações geográficas para o Brasil. Jornal a Vindima - O Jornal da Vitivinicultura Brasileira, Flores da Cunha, jun./jul. p.16-17, 2008. 
CAMARGO, U. A.; TONIETO, J.; HOFFMANN, A. Progressos na viticultura brasileira. Revista Brasileira de Fruticultura, volume especial, p. 144-149, 2011.

CERDAN, C. As Indicações geográficas no Brasil: situação e perspectivas. In: II Seminário Internacional de Indicação Geográfica: produtos de origem como estratégia de desenvolvimento, 2010, João Pessoa, PB. Anais... João Pessoa: Ministério da Agricultura - Sebrae, 2010. 1 CD-ROM.

CHAMPREDONDE, M. Les Indications Géographiques (IG) en Amérique Latine: etats des lieux, perspectives et défis. In : Symposium International sur l'agriculture biologique mediterraneenne et les institut... distinctifs de qualite lies a l'origine, 2013, Agadir, Marrocos. Anais... Agadir: Institut Agronomique et Vétérinaire Hassan II Organisation des Nations Unies pour l'Alimentation et l'Agriculture, 2013. 1 CD-ROM.

\section{DIREÇÃO GERAL DE AGRICULTURA E DESENVOLVIMENTO RURAL. Ananás dos Açores/São Miguel DOP. Disponível em: https://tradicional.dgadr.gov.pt/pt/cat/frutos-frescos/934-ananas-dos-acores-sao- miguel-dop. Acesso em: 15 jan. 2014.}

FIALHO, M. A. V.; WAQUIL, P. D. O desenvolvimento rural: concepções e referências para a proposição de políticas públicas de desenvolvimento nos territórios rurais. Extensão Rural, Santa Maria, n. 15, p. 129-165, jan./jun. 2008. Disponível em: <http://coralx.ufsm.br/extensaorural/art6ed15.pdf>. Acesso em : 15 set. 2017.

FISCHLER, C. L’homnivore. Paris: Editions Odile-Jacob, 1990.

FOURNIER, S. et al. Le développement des indications au sud : attentes des acteurs locaux et fonctions jouées. Etudes de cas en Indonésie et en Ethiopie. In : Congres International localiser les produits: une voie durable au service de la diversite naturelle et culturelle des suds?, 2009, Paris, França. Anais... Paris: Unesco, 2009. 1 CD-ROM.

FREITAS, A. F.; FREITAS, A. F. Representações sociais como condicionantes dos processos de desenvolvimento territorial. Extensão Rural, Santa Maria, v. 23, n. 1, p. 93-115, jan./mar. 2016. Disponível em: <https://periodicos.ufsm.br/extensaorural/article/view/18130/pdf>. Acesso em: 15 set. 2017.

GABRIEL, P.; URIEN, B. Valeurs de consommation et origine territoriale des produits. Décisions Marketing, n. 43/44, p. 41-54, 2006.

GIOVANNUCCI, D. Et al. Guide des indications géographiques: faire le lien entre les produits et leurs origines. Genbra: Centre du commerce international, 2009.

GUIA. Turismo e viagem Salvador, Bahia e Nordeste. Disponível em: http://www.bahia.ws/guia-turismo-serido-sertao-rn/. Acesso em: 01 ago. 2017.

INSTITUT NATIONAL DE L'ORIGINE ET DE LA QUALITE. INSTITUT. "Pomme du Limousin". $2012 . \quad$ Disponível em: 
http://www.inao.gouv.fr/public/produits/detailProduit.php?ID_PRODUIT=12229\&from =src. Acesso em: 26 mar. 2014.

INSTITUT NATIONAL DE L'ORIGINE ET DE LA QUALITE. Les Institut de I'identification de la Qualité et de l'Origine. s/d. Disponível em: http://www.inao.gouv.fr/public/home.php?pageFromlndex=textesPages/Les_INSTITU T..._de_la_Qualite_et_de_I_Origine376.php mnu=376. Acesso em: 26 mar. 2014

INSTITUTO NACIONAL DE PROPRIEDADE INDUSTRIAL. O que é indicação geográfica? 2010. Disponível em: http://www.inpi.gov.br/menuesquerdo/indicacao/o-que-e-indicacao-geografica. Acesso em: 12 dez. 2013.

LIMA, M. A. C. Subsídios técnicos para a indicação geográfica de procedência do Vale do Submédio São Francisco. Petrolina: Embrapa Semi-Árido, 2009.

LINK, T.; LÓPEZ, E. B.; CASABIANCA, F. De la propiedad intelectual a la calificación de los territorios: Lo que cuentan los quesos tradicionales. Agroalimentaria, v. 11, n. 22, p. 99-109, 2006.

MASCARENHAS, G. Políticas de desenvolvimento territorial e IG. In: II Seminário Internacional de Indicação Geográfica: produtos de origem como estratégia de desenvolvimento, 2010, João Pessoa, PB. Anais... João Pessoa: Ministério da Agricultura - Sebrae, 2010. 1 CD-ROM.

MATOS, L. I.; La ROVERE, R. L. As diferentes interpretações dos conceitos de indicações geográficas por instituições brasileiras. Desenvolvimento Regional em Debate, v. 7, n. 1, p. 4-24, 2017.

PARROT, N.; WILSON, N.; MURDOCH, J. Spatializing quality: regional protection and the alternative geography of food. European Urban and Regional Studies, v. 9, n. 3, p. 241-261, 2002.

SANTOS, R. F. A cultura dos ananás dos Açores/São Miguel. Revista da Associação Portuguesa de Horticultura, n. 101, p. 38-40, 2010.

SANTOS, J. S. Dilemas e desafios na valorização de produtos alimentares tradicionais no Brasil: um estudo a partir do Queijo do Serro, em Minas Gerais, e do Queijo Serrano, no Rio Grande do Sul. 2014. Tese (Doutorado em Agronomia) Programa de Pós-Graduação em Sistemas de Produção Agrícola Familiar, Universidade Federal de Pelotas.

SANZ-CAÑADA, J.; VÁSQUEZ, A. M. Quality certification, institutions and innovation in local agro-food systems: Protected Designations of Origin of olive oil in Spain. Journal of Rural Studies, v. 21, n. 4, p. 475-486, 2005.

TIBÉRIO, L.; FRANCISCO, D. Agri-food traditional products: from certification to the market - portuguese recent evolution. Regional Science Inquiry Journal, v. 4, n. 2, p. 57-86, 2012.

TREGEAR, A.; FILIPPO, A.; BELLETTIC, G.; MARESCOTTI, A. Regional foods and rural development: The role of product qualification. Journal of Rural Studies, v. 23, n. 1, p. 12-22, 2007. 
VALSESCHINI, E. La dénomination d'origine comme signal de qualité crédible.

Revue d'Economie Régionale et Urbaine, n. 3, p. 489-500, 2000. 